\title{
Combination of sufentanil, dexmedetomidine and ropivacaine to improve epidural labor analgesia effect: A randomized controlled trial
}

\author{
GEHUI LI ${ }^{1 *}$, YUCI XIAO ${ }^{1 *}$, XIAOFEI QI ${ }^{1}$, HAO WANG $^{2}$, XIAOGUANG WANG ${ }^{1}$, \\ JING SUN ${ }^{1}$, YONG LI ${ }^{1}$ and YUANTAO LI ${ }^{1}$ \\ ${ }^{1}$ Department of Anesthesiology, Shenzhen Maternity and Child Healthcare Hospital, Southern Medical University, \\ Shenzhen, Guangdong 518028; ${ }^{2}$ Department of Food Safety, Market Supervision Administration of \\ Shenzhen Municipality, Shenzhen, Guangdong 518040, P.R. China \\ Received October 31, 2019; Accepted February 14, 2020
}

DOI: $10.3892 /$ etm.2020.8730

\begin{abstract}
Opioids and $\alpha 2$-agonists have been used as epidural adjuvants in local anesthetics for a long time, but the effect of the combination of opioids and $\alpha 2$-agonists as epidural adjuvants is not completely understood. In the present study, the combination of dexmedetomidine (Dex) and sufentanil as adjuvants to ropivacaine for epidural labor analgesia was investigated. A total of 108 parturient women receiving labor epidural analgesia were randomly divided into three groups: i) Group $\mathrm{RD}$ received $0.1 \%$ ropivacaine $+0.5 \mu \mathrm{g} / \mathrm{ml} \mathrm{Dex}$; ii) Group RS received $0.1 \%$ ropivacaine $+0.5 \mu \mathrm{g} / \mathrm{ml}$ sufentanil; and iv) Group RDS received $0.1 \%$ ropivacaine $+0.25 \mu \mathrm{g} / \mathrm{ml}$ Dex $+0.25 \mu \mathrm{g} / \mathrm{ml}$ sufentanil. Patients received a $10 \mathrm{ml}$ loading dose followed by a maintenance by patient controlled epidural analgesia. The visual analog scale scores, onset time, local anesthetic requirements, motor blockage and adverse effects were recorded. Group RDS displayed an improved labor analgesia effect compared with Groups RD and RS. Group RDS displayed a shorter onset time compared with Groups RD and $\mathrm{RS}$, and a reduced local anesthetic requirement compared with Group RS. The motor blockage in Groups RDS and RS was significantly lower compared with Group RD, and the incidence of pruritus in Groups RDS and RD was lower compared with Group RS. In conclusion, the combined use of $0.25 \mu \mathrm{g} / \mathrm{ml}$ Dex and $0.25 \mu \mathrm{g} / \mathrm{ml}$ sufentanil as adjuvants to $0.1 \%$ ropivacaine for epidural labor analgesia displayed an improved analgesia
\end{abstract}

Correspondence to: Dr Yuantao Li, Department of Anesthesiology, Shenzhen Maternity and Child Healthcare Hospital, Southern Medical University, 2004 Hongli Road, Shenzhen, Guangdong 518028, P.R. China

E-mail: yuantaoli6788@126.com

*Contributed equally

Key words: anesthesia, epidural, labor pain, dexmedetomidine, sufentanil effect compared with the use of either $0.5 \mu \mathrm{g} / \mathrm{ml}$ sufentanil or $0.5 \mu \mathrm{g} / \mathrm{ml}$ Dex alone. The present study was registered with the Chinese Clinical Trial Registry Center on 23 February, 2018 (registration no. ChiCTR-IOR-1800014943).

\section{Introduction}

Delivery pain has been reported to be one of the most painful experiences of the majority of women, which can cause potential harm to both the mother and the baby (1-3). Epidural blockade is the most effective method of labor analgesia, which facilitates painless labor and can be customized for each patient (4). However, there are also a number of disadvantages associated with epidural labor analgesia, including motor blockade, a lengthened second stage of labor and hypotension (5). Anesthetists have been seeking strategies to improve the effects of analgesia and avoid the aforementioned side effects, and the use of opioids and $\alpha 2$-adrenoreceptor agonists as adjuvant drugs is an example $(6,7)$.

Sufentanil and dexmedetomidine (Dex) have been used individually as adjuvants to ropivacaine for epidural labor analgesia to alleviate the side effects. Debon et al (8) reported that the use of sufentanil as an adjuvant increased the duration of epidural labor analgesia. The use of opioids as adjuvants results in a high incidence of respiratory depression, urinary retention, nausea, vomiting and pruritus. The safety of epidural and spinal administration of Dex has been demonstrated in humans, where epidural administration was hypothesized to block sympathetic nerve slower and therefore, increased safely $(9,10)$. Compared with ropivacaine alone, the addition of Dex as an adjuvant to epidural ropivacaine can reduce the feeling of pain, but does not result in motor blockage (11). In addition, Zhang et al (12) reported that the analgesic effect and duration of the first stage of labor during epidural analgesia (EA) with $0.1 \%$ ropivacaine + Dex was superior compared with $0.1 \%$ ropivacaine + sufentanil. In previous studies, intrathecal Dex lengthened the sensory and motor blockage during hysteroscopic surgery and cesarean sections $(13,14)$. Therefore, it has been hypothesized that the combination of Dex and sufentanil as epidural adjuvants could enhance the 
beneficial effects of each adjuvant. To the best of our knowledge, the present study investigated for the first time whether the combination of Dex and sufentanil in labor analgesia could improve the effects of analgesia and decrease the incidence of associated side effects. The results of the present study may provide insight into epidural blockade and provide a novel strategy for labor analgesia.

\section{Materials and methods}

Study subjects. The present randomized, double-blinded, prospective, controlled trial was performed at Shenzhen Maternity and Child Healthcare Hospital, Southern Medical University. The present study was approved by the Shenzhen Maternity and Child Healthcare Hospital Ethics Committee (approval no. SZFY2018020798).

All parturient women undergoing vaginal delivery and requesting labor analgesia in the hospital between March 2018 and October 2018 were considered for inclusion. The inclusion criteria were as follows: i) Aged 20-35 years; ii) American Society of Anesthesiology Physical Status I/II (15); iii) a single fetus; iv) $\geq 37$ gestation weeks; v) cervical dilatation of $3 \mathrm{~cm}$; and vi) provided written informed consent. The exclusion criteria were as follows: i) Refusal to participate; ii) aged $<18$ years; iii) endocrine diseases, obesity, hypertension or hypotension; iv) fetal compromise; v) allergy to study agents; or vi) an inability to communicate. Furthermore, if the epidural anesthesia failed, the epidural catheter was dislodged, an inadvertent epidural puncture occurred or a rapid progress in labor occurred (delivery in $<120 \mathrm{~min}$ ), the patient was excluded from the final analysis.

Group allocation. Written informed consent was obtained from all included parturient women. A total of 108 parturient women were assigned to three groups: i) Group RD received $0.1 \%$ ropivacaine $+0.5 \mu \mathrm{g} / \mathrm{ml}$ Dex; ii) Group RS received $0.1 \%$ ropivacaine $+0.5 \mu \mathrm{g} / \mathrm{ml}$ sufentanil; and iv) Group RDS received $0.1 \%$ ropivacaine $+0.25 \mu \mathrm{g} / \mathrm{ml}$ Dex $+0.25 \mu \mathrm{g} / \mathrm{ml}$ sufentanil . All treatments were administered by epidural injection.

Parturient women were randomly assigned to the three treatment groups by an independent investigator using a computer-generated random number table. The grouping assignment was sealed in envelopes and not opened until just before the anesthesia was administered. To maintain blinding, the investigators and patients were not informed of the group assignments.

Sample size. Based on the preliminary data (data not shown), the visual analog scale (VAS) score (16) at $10 \mathrm{~min}$ after epidural placement [mean (standard deviation)] in the RS group was 5.0 (2.5), which was reduced to 3.7 (2.1) in the RDS group. By setting the VAS score as the primary variable, 30 patients were assigned to each group with a statistical significance of 0.05 and a power of 90\%. To compensate for possible dropouts or excluded cases, 36 parturient women were assigned to each group.

Procedures. To eliminate any possible effects of anesthetic technique, the same anesthetist group performed all procedures. When cervical dilatation reached $3 \mathrm{~cm}$, EA was performed at the L2/L3 intervertebral space using a 16G epidural needle to insert an epidural catheter 3-4 $\mathrm{cm}$ into the epidural space. Following the administration of a test dose of $3 \mathrm{ml} 1 \%$ lidocaine for $5 \mathrm{~min}$, parturients received $10 \mathrm{ml} 0.5 \mu \mathrm{g} / \mathrm{ml} \mathrm{Dex}$ (Group RD), $0.5 \mu \mathrm{g} / \mathrm{ml}$ sufentanil (Group RS) or $0.25 \mu \mathrm{g} / \mathrm{ml}$ Dex $+0.25 \mu \mathrm{g} / \mathrm{ml}$ sufentanil (Group RDS), together with $0.1 \%$ ropivacaine as the loading dose. The maintenance of patient controlled EA was administered after the loading dose using an Apon PCA pump (Jiangsu Apon Medical Technology Co., Ltd.). The pumps were set at a rate of $7 \mathrm{ml} / \mathrm{h}$ with a rescue bolus of $7 \mathrm{ml}$ (lockout $25 \mathrm{~min}$; limit $25 \mathrm{ml} / \mathrm{h}$ ). Patients experiencing inadequate analgesia could request an additional $5 \mathrm{ml}$ bolus of the medication solution, via epidural administration by the nurse.

If hypotension $(90 / 60 \mathrm{mmHg})$ occurred, the patient was placed in a left-leaning position or phenylephrine was administered as a vasoconstrictor active drug. After delivery, the administration of the drugs was terminated and the epidural catheter was removed.

Data collection. The demographic and baseline measurements, including age, height, weight and gestational age, were recorded. In the present study, the VAS score ( 0 , no pain; 10 , most serious pain) was evaluated prior to epidural placement (baseline) and at 5, 10, 20, 30, 60, 90 and 120 min after the loading dose was injected. The administration of the loading dose was considered to be $0 \mathrm{~min}$. The time of onset, which was defined as the duration between the end of drug administration and the patient displaying a VAS score $<3$, was observed. The duration of each labor period (active period, second stage and third stage), Apgar score (11), umbilical vein $\mathrm{pH}$, cesarean delivery rate, bolus frequency and total volume of anesthetic solution were also recorded. Evaluation of motor blockage was conducted using the Bromage scoring system (1, able to lift the legs above the table; 2 , able to bend the knees; 3 , able to move the feet only; 4, no movement in the feet or legs) (7). Additionally, hypotension (systolic blood pressure $<90 \mathrm{mmHg}$ or $<30 \%$ of the base value), bradycardia (heart rate $<60 \mathrm{bpm}$ ), nausea, vomiting, shivering and pruritus were monitored.

In the present study, the primary outcome was the VAS score, and the secondary outcomes were the onset time, duration of each labor stage, Apgar score, cesarean delivery rate, bolus frequency, total volume of anesthetic solution, Bromage score and other side effects.

Statistical analysis. Statistical analyses were conducted using SPSS software (version 20.0; IBM Corp.). The one-sample Kolmogorov-Smirnov test was used to assess the normality of the quantitative data. Quantitative variables are presented as the mean \pm standard deviation and categorical variables are presented as numbers (\%; n, \%). Quantitative variables were analyzed using one-way ANOVA followed by the Bonferroni post hoc test. Categorical variables were analyzed using the $\chi^{2}$ test or Fisher's exact test. $\mathrm{P}<0.05$ was considered to indicate a statistically significant difference.

\section{Results}

Patient variables. A total of 108 parturient women were recruited into the present study; however, one woman was excluded during the study due to a protocol deviation resulting in a suspected 


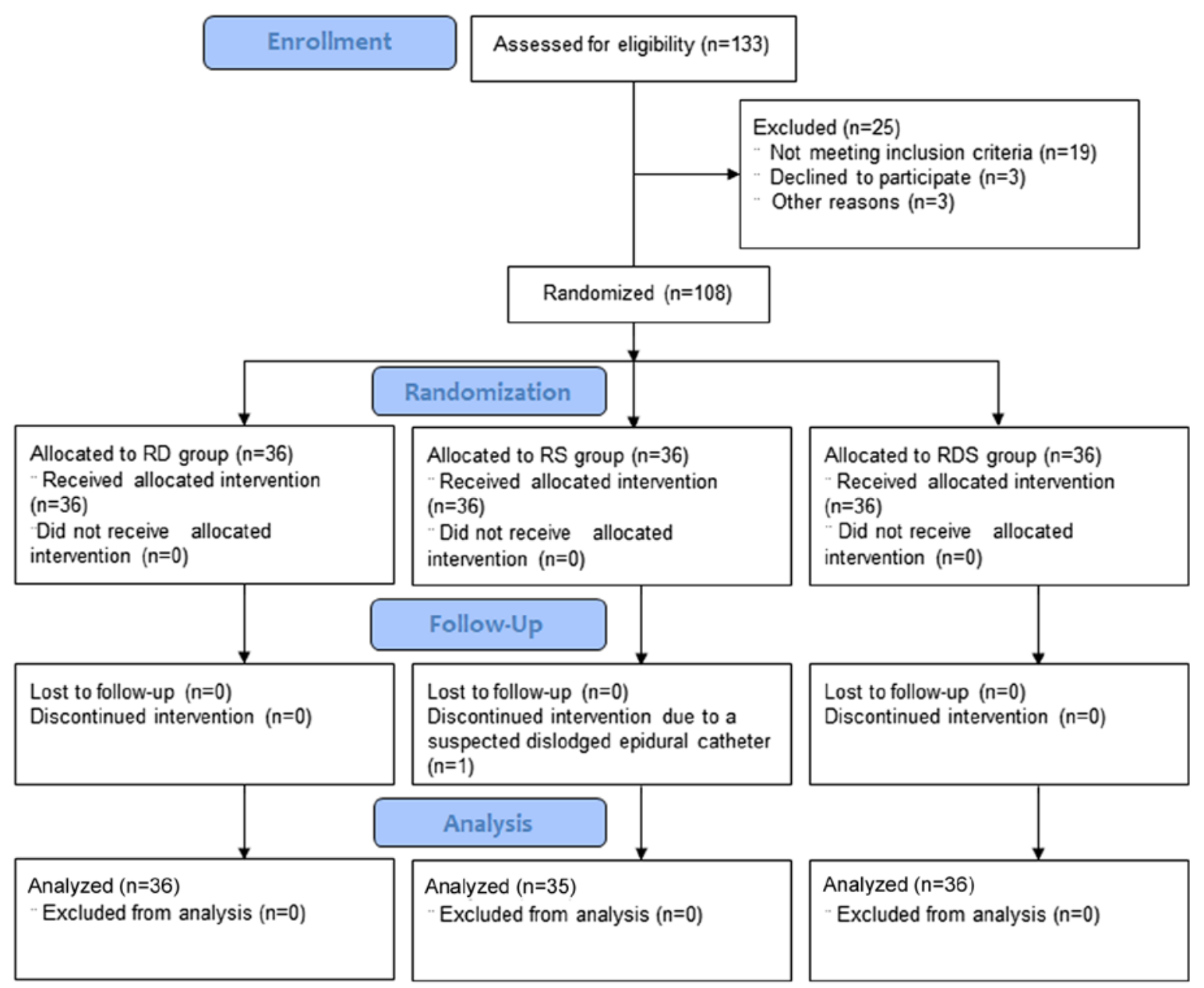

Figure 1. Consolidated Standards of Reporting Trials flow chart. Blue boxes represent the committed step of the clinical trial. RS, sufentanil + ropivacaine epidural; RD, dexmedetomidine + ropivacaine epidural; RDS, dexmedetomidine + sufentanil + ropivacaine epidural.

dislodged epidural catheter. Therefore, 107 parturient women were included in the final analysis among the RD, RS and RDS groups (Fig. 1). The demographic variables of the parturient women in the three groups were comparable, including age, height, weight and gestational age ( $\mathrm{P}>0.05$; Table I).

Primary outcomes. The VAS scores at $10 \mathrm{~min}$ after epidural placement in Groups RDS $(2.44 \pm 1.27$ vs. $5.13 \pm 2.74 ; \mathrm{P}<0.001)$ and $\mathrm{RD}(3.67 \pm 2.71$ vs. $5.13 \pm 2.74 ; \mathrm{P}<0.05)$ were significantly decreased compared with Group RS (Table II). Furthermore, at the 5, 10, 20, 30, 60, 90 and 120 min time points, Group RDS displayed significantly lower VAS scores compared with Group RS ( $\mathrm{P}<0.05$; Table II and Fig. 2). In addition, the VAS scores in Group RDS were significantly lower compared with Group RD at 20 and $30 \mathrm{~min}(\mathrm{P}<0.05$; Table II and Fig. 2). Group RD also displayed significantly lower VAS scores compared with Group RS at 10, 60, 90 and 120 min $(\mathrm{P}<0.05$; Table II and Fig. 2).

Secondary outcomes. The parturient women in the three groups were comparable for the following factors: Duration of each labor stage, Apgar scores, umbilical vein $\mathrm{pH}$ and cesarean delivery rate $(\mathrm{P}>0.05$; Table III). In addition, no patient experienced inadequate analgesia; therefore, the additional $5 \mathrm{ml}$ bolus analgesia was not administered to any of the patients.
The onset time of Group RDS was significantly shorter compared with Groups RS and RD $(\mathrm{P}<0.05)$, and the parturient women in Groups RDS and RD required a reduced injection volume and fewer local anesthetic administrations compared with Group RS $(\mathrm{P}<0.05$; Table IV). Motor blockage in Group RD was more severe compared with Groups RS (9/19/2/0 vs. $27 / 2 / 1 / 0 ; \mathrm{P}<0.001)$ and $\operatorname{RDS}(9 / 19 / 2 / 0$ vs. $22 / 8 / 0 / 0 ; \mathrm{P}<0.001$; Table IV). Additionally, the incidence of pruritus was significantly lower in Groups RD and RDS compared with Group RS $(\mathrm{P}<0.05$; Table V).

There were no statistical differences in the proportion of patients with nausea, vomiting, shivering, bradycardia, hypotension and urinary retention among the three groups $(\mathrm{P}>0.05$; Table V).

\section{Discussion}

Labor pain is a complicated sensory reaction that occurs during delivery. EA with local anesthetics is the main strategy used to induce labor analgesia, and the most representative adjuvants used in clinical practice for labor analgesia are opioids and $\alpha 2$-adrenergic receptor agonists $(17,18)$. Compared with the use of $0.1 \%$ ropivacaine $+0.5 \mu \mathrm{g} / \mathrm{ml}$ Dex or $0.5 \mu \mathrm{g} / \mathrm{ml}$ sufentanil, $0.1 \%$ ropivacaine in combination with $0.25 \mu \mathrm{g} / \mathrm{ml}$ Dex and $0.25 \mu \mathrm{g} / \mathrm{ml}$ sufentanil resulted in an improved labor 
Table I. Demographic baseline variables.

\begin{tabular}{lcccc}
\hline Variable & Group RS $(\mathrm{n}=35)$ & Group RD $(\mathrm{n}=36)$ & Group RDS $(\mathrm{n}=36)$ & P-value \\
\hline Age (years) & $30.13 \pm 4.86$ & $29.23 \pm 3.88$ & $30.83 \pm 3.77$ & 0.340 \\
Height $(\mathrm{cm})$ & $159.03 \pm 4.49$ & $159.61 \pm 5.13$ & $159.70 \pm 4.42$ & 0.829 \\
Weight $(\mathrm{kg})$ & $64.73 \pm 8.85$ & $65.21 \pm 7.15$ & $66.35 \pm 9.01$ & 0.756 \\
Gestational age (weeks) & $37.41 \pm 3.94$ & $39.10 \pm 0.91$ & $38.22 \pm 2.92$ & 0.063 \\
\hline
\end{tabular}

Data are presented as the mean \pm SD. Patients were randomly assigned to the three groups. RS, sufentanil + ropivacaine epidural; RD, dexmedetomidine + ropivacaine epidural; RDS, dexmedetomidine + sufentanil + ropivacaine epidural.

Table II. Visual Analog scale at different time points.

\begin{tabular}{|c|c|c|c|c|}
\hline Time (min) & Group RS $(\mathrm{n}=35)$ & Group RD $(n=36)$ & Group RDS (n=36) & P-value \\
\hline Baseline & $8.90 \pm 1.60$ & $8.81 \pm 1.54$ & $8.69 \pm 1.15$ & 0.822 \\
\hline 5 & $6.72 \pm 2.33$ & $5.71 \pm 3.33$ & $5.35 \pm 1.72^{\mathrm{a}}$ & 0.103 \\
\hline 10 & $5.13 \pm 2.74$ & $3.67 \pm 2.71^{\mathrm{a}}$ & $2.44 \pm 1.27^{b}$ & 0.000 \\
\hline 20 & $2.99 \pm 1.44$ & $2.87 \pm 1.53$ & $1.84 \pm 1.15^{\mathrm{a}, \mathrm{c}}$ & 0.013 \\
\hline 30 & $2.98 \pm 1.75$ & $2.80 \pm 2.16$ & $1.72 \pm 1.07^{\mathrm{a}, \mathrm{c}}$ & 0.011 \\
\hline 60 & $3.46 \pm 2.18$ & $2.17 \pm 1.24^{\mathrm{a}}$ & $1.75 \pm 1.17^{\mathrm{a}}$ & 0.004 \\
\hline 90 & $3.11 \pm 1.68$ & $2.20 \pm 1.51^{\mathrm{a}}$ & $1.74 \pm 1.22^{\mathrm{a}}$ & 0.009 \\
\hline 120 & $3.46 \pm 1.47$ & $2.23 \pm 1.40^{\mathrm{a}}$ & $1.53 \pm 1.05^{\mathrm{b}}$ & 0.000 \\
\hline
\end{tabular}

Data are presented as the mean $\pm \mathrm{SD}$. Patients were randomly assigned to the three groups. ${ }^{\mathrm{a}} \mathrm{P}<0.05$ and ${ }^{\mathrm{b}} \mathrm{P}<0.001 \mathrm{vs}$. Group $\mathrm{RS}$. ${ }^{\mathrm{C}}<0.05$ vs. Group RD. RS, sufentanil + ropivacaine epidural; RD, dexmedetomidine + ropivacaine epidural; RDS, dexmedetomidine + sufentanil + ropivacaine epidural.

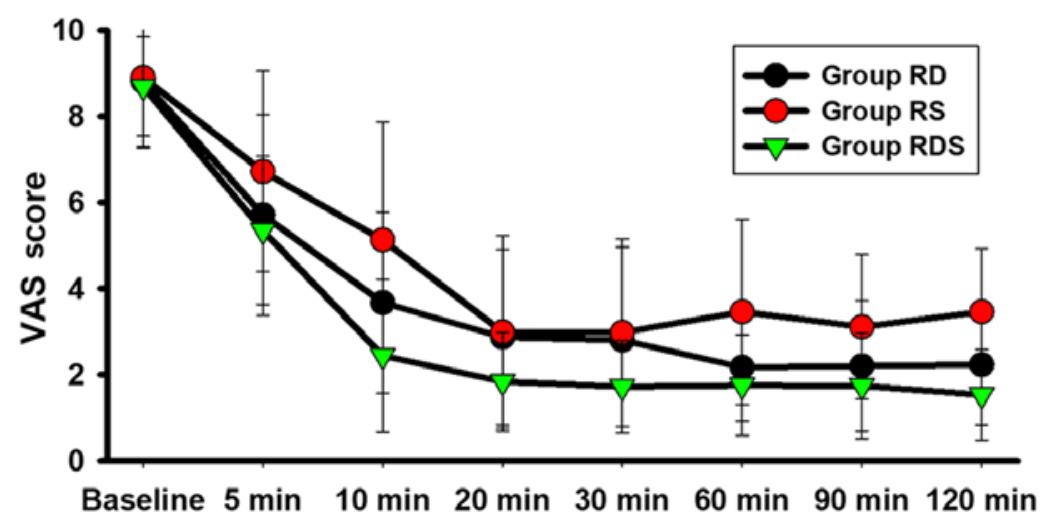

Figure 2. VAS among the three groups. Data are presented as the mean \pm SD. Patients were randomly assigned to the three groups. The VAS score $(0$, no pain; 10, most serious pain) was evaluated before epidural placement (baseline), and 5, 10, 20, 30, 60, 90 and 120 min after the loading dose was injected, which was considered to be 0 min. VAS, Visual Analog Scale; RS, sufentanil + ropivacaine epidural; RD, dexmedetomidine + ropivacaine epidural; RDS, dexmedetomidine + sufentanil + ropivacaine epidural.

analgesia effect, quicker onset time, reduced need for local anesthetics and fewer side effects.

Sufentanil has been used as local anesthetic adjuvant in epidural labor analgesia in a number of previous studies $(1,12)$; therefore, sufentanil in combination with ropivacaine was used as the positive control in the present study. Dex has also been reported to display hemodynamic stability, pain alleviation, improved stress responses without respiratory depression when administered intravenously and intratracheally $(19,20)$, and improved epidural and neuraxial blocks $(21,22)$. Zhao et al (11) reported that compared with ropivacaine alone, the addition of Dex to epidural ropivacaine reduced the feeling of pain and did not result in motor blockage. Abdallah et al (23) also reported that both perineural and intravenous Dex effectively prolonged the interscalene brachial plexus block analgesic duration 
Table III. Data of parturient women and neonatal outcome.

\begin{tabular}{lccr}
\hline Variable & Group RS (n=35) & Group RD (n=36) & Group RDS (n=36) \\
\hline Duration of the first labor stage (min) & $396.11 \pm 14.56$ & $347.93 \pm 10.15$ & $396.26 \pm 9.37$ \\
Duration of the second labor stage (min) & $30.59 \pm 7.67$ & $52.54 \pm 6.49$ & $42.74 \pm 6.799$ \\
Duration of the third labor stage (min) & $10.92 \pm 6.38$ & $10.46 \pm 7.82$ & $11.59 \pm 10.07$ \\
Apgar score & & & 0.819 \\
1 min $\geq 7$ & $35(100)$ & $36(100)$ & $36(100)$ \\
5 min $\geq 9$ & $35(100)$ & $36(100)$ & $36(100)$ \\
Umbilical vein pH & $7.21 \pm 0.08$ & $7.21 \pm 0.02$ & 1.000 \\
Cesarean delivery $(\%)$ & 13.3 & 10.0 & 1.000 \\
& & 0.793 \\
\end{tabular}

${ }^{a}$ Apgar Score was measured twice for each of the newborns-once after $1 \mathrm{~min}$, and again at $5 \mathrm{~min}$. Data are presented as the mean $\pm \mathrm{SD}$ or number $(\%)$. Patients were randomly assigned to the three groups. RS, sufentanil + ropivacaine epidural; RD, dexmedetomidine + ropivacaine epidural; RDS, dexmedetomidine + sufentanil + ropivacaine epidural.

Table IV. Onset time, local anesthetic requirement and Bromage score.

\begin{tabular}{|c|c|c|c|c|}
\hline Variable & Group RS $(n=35)$ & Group RD (n=36) & Group RDS $(n=36)$ & P-value \\
\hline Onset time $(\min )$ & $15.50 \pm 2.67$ & $12.97 \pm 3.13$ & $9.68 \pm 1.26^{\mathrm{a}, \mathrm{c}}$ & 0.037 \\
\hline Total volume of anesthetic solution (ml) & $65.44 \pm 5.64$ & $42.65 \pm 6.44$ & $50.34 \pm 6.56^{\mathrm{a}}$ & 0.043 \\
\hline Bolus frequency & $2.80 \pm 0.92$ & $0.10 \pm 0.31^{\mathrm{a}}$ & $0.80 \pm 0.78^{a}$ & 0.026 \\
\hline Bromage score $(1 / 2 / 3 / 4)$ & $27 / 2 / 1 / 0$ & $9 / 19 / 2 / 0^{\mathrm{b}}$ & $22 / 8 / 0 / 0^{\mathrm{d}}$ & 0.000 \\
\hline
\end{tabular}

Data are presented as the mean \pm SD or number. Patients were randomly assigned to the three groups. ${ }^{a} \mathrm{P}<0.05$ and ${ }^{b} \mathrm{P}<0.001$ vs. Group RS ${ }^{\mathrm{c}} \mathrm{P}<0.05$ and ${ }^{\mathrm{d}} \mathrm{P}<0.001$ vs. Group RD. RS, sufentanil + ropivacaine epidural; RD, dexmedetomidine + ropivacaine epidural; RDS, dexmedetomidine + sufentanil + ropivacaine epidural.

Table V. Adverse events among the three groups.

\begin{tabular}{lcccc}
\hline Event & $\begin{array}{c}\text { Group RS } \\
(\mathrm{n}=35)(\%)\end{array}$ & $\begin{array}{c}\text { Group RD } \\
(\mathrm{n}-36)(\%)\end{array}$ & $\begin{array}{c}\text { Group RDS } \\
(\mathrm{n}=36)(\%)\end{array}$ & P-value \\
\hline Hypotension & $0(0.0)$ & $1(2.8)$ & $0(0.0)$ & 1.000 \\
Bradycardia & $0(0.0)$ & $1(2.8)$ & $0(0.0)$ & 1.000 \\
Nausea & $1(2.9)$ & $0(0.0)$ & $0(0.0)$ & 0.327 \\
Vomiting & $1(2.9)$ & $1(2.8)$ & $0(0.0)$ & 0.771 \\
Shivering & $2(5.7)$ & $3(8.3)$ & $2(5.6)$ & 1.000 \\
Pruritus & $5(14.3)$ & $0(0.0)^{\mathrm{a}}$ & $0(0.0)^{\mathrm{a}}$ & 0.003 \\
Urinary & $2(5.7)$ & $2(5.6)$ & $1(2.8)$ & 0.869 \\
retention & & & & \\
\hline
\end{tabular}

Data are presented as the number (\%). Patients were randomly assigned to the three groups. ${ }^{\mathrm{a}} \mathrm{P}<0.05$ vs. Group RS. RS, sufentanil + ropivacaine epidural; $\mathrm{RD}$, dexmedetomidine + ropivacaine epidural; RDS, dexmedetomidine + sufentanil + ropivacaine epidural.

and reduced sufentanil consumption without prolonging motor blockade. By contrast, certain studies have indicated that intrathecal Dex lengthens sensory and motor blockage during hysteroscopic surgery and cesarean sections $(13,14)$, and the addition of epidural opioids results in a high inci- dence of respiratory depression, urinary retention, nausea, vomiting and pruritus (24,25). Qin et al (26) also reported that the combination of Dex and sufentanil for postoperative analgesia in patients with partial laryngectomy resulted in significantly reduced sufentanil consumption, improved analgesia, a reduced frequency of coughing episodes and improved sleep quality. To the best of our knowledge, the present study was the first study to investigate the combination of epidural Dex and sufentanil in labor analgesia. In the present study, Group RDS displayed lower VAS scores compared with Group RS at all time points, and compared with Group RD at 20 and 30 min after epidural placement. The results indicated that the combined administration of Dex and sufentanil as adjuvants to local anesthetic displayed an improved analgesic effect compared with the use of either drug alone.

Both $0.5 \mu \mathrm{g} / \mathrm{ml}$ Dex and $0.5 \mu \mathrm{g} / \mathrm{ml}$ sufentanil have been used as adjuvants in clinical practice $(12,27)$. In the present study, the combination of $0.25 \mu \mathrm{g} / \mathrm{ml}$ Dex $+0.25 \mu \mathrm{g} / \mathrm{ml}$ sufentanil + $0.1 \%$ ropivacaine was administered via an epidural for labor analgesia, and the efficiency and safety of the combined treatment was compared with $0.1 \%$ ropivacaine $+0.5 \mu \mathrm{g} / \mathrm{ml}$ Dex or $0.5 \mu \mathrm{g} / \mathrm{ml}$ sufentanil. The dose used in the present study was determined according to a preliminary study, which indicated that for epidural labor analgesia the optimal concentration of Dex was $0.5 \mu \mathrm{g} / \mathrm{ml}$ when combined with $0.1 \%$ ropivacaine; 
therefore, $0.5 \mu \mathrm{g} / \mathrm{ml}$ Dex was used as an adjuvant to epidural ropivacaine in labor analgesia. Furthermore, the addition of $5 \mu \mathrm{g}$ intrathecal Dex to $10 \mu \mathrm{g}$ fentanyl lengthened the analgesia duration and lowered the incidence of adverse effects compared with the use of intrathecal $10 \mu \mathrm{g}$ Dex or intrathecal $20 \mu \mathrm{g}$ fentanyl alone (28). Therefore, $0.25 \mu \mathrm{g} / \mathrm{ml}$ Dex and $0.25 \mu \mathrm{g} / \mathrm{ml}$ sufentanil were used as adjuvants in combination with $0.1 \%$ ropivacaine epidurally for labor analgesia in the present study.

Koraki et al (29) reported that the onset time of epidural Dex combined with ropivacaine was $\sim 15 \mathrm{~min}$, which was longer compared with the results of the present study. The inconsistency could be explained by the different ropivacaine concentrations used in each study. The combined use of ropivacaine, $0.25 \mu \mathrm{g} / \mathrm{ml}$ Dex and $0.25 \mu \mathrm{g} / \mathrm{ml}$ sufentanil displayed a quicker onset time, enhanced the analgesic effect, decreased the VAS scores, reduced the bolus frequency and limited motor blockage without causing adverse side effects compared with the use of either adjuvants alone. The results indicated that Dex synergized with sufentanil systemically and regionally, which was consistent with previously reported clinical results $(26,30)$.

The analgesic effect of Dex is not completely understood. Eisenach et al (31) reported that Dex is present in the cerebrospinal fluid rapidly after administration and binds highly to $\alpha 2$-receptors in the spinal cord. Marhofer et al (32) demonstrated that the analgesic effect of Dex was primarily mediated at the spinal level; therefore, epidural administration is recommended. Yang et al (33) reported that intraperitoneal Dex displayed a dose-dependent analgesic effect by inhibiting hyperpolarization-activated cyclic nucleotide-gated currents. Recently, Sun et al (34) reported that the analgesic effects of Dex were associated with its anti-inflammatory effect. The aforementioned studies indicated that Dex exerts analgesic effects not only via $\alpha 2$-adrenergic receptors, but also by direct channel inhibition via an $\alpha 2$-independent mechanism, which enables Dex to serve as an analgesic adjuvant. A recent systematic review and meta-analysis demonstrated that the use of Dex as an adjuvant in epidural procedures is generally safe and well tolerated (35).

Compared with the combination of Dex and sufentanil, $0.5 \mu \mathrm{g} / \mathrm{ml}$ epidural Dex weakened muscle strength and induced more severe motor block, which was consistent with previous studies $(13,14)$. Furthermore, the incidence of pruritus observed in the present study was similar to the incidence reported by Boselli et al (36). No significant intergroup differences were detected for the three stages of labor, umbilical vein $\mathrm{pH}$ or Apgar scores, which was consistent with previous studies $(7,37,38)$.

The present study had a number of limitations. Firstly, the present study only investigated the efficiency and safety of $0.25 \mu \mathrm{g} / \mathrm{ml}$ Dex and $0.25 \mu \mathrm{g} / \mathrm{ml}$ sufentanil as adjuvants to $0.1 \%$ ropivacaine; therefore, further studies should be performed using different doses of epidural Dex and sufentanil. Secondly, the present study was a single-center clinical trial and the preliminary results should be verified by a large-scale multicenter study. Thirdly, although Dex has been widely used as an epidural drug in clinical practice and has been reported to display no significant adverse reactions, it is still not licensed for epidural use. In particular, the safety of Dex needs to be investigated in a large-scale phase IV clinical trial. Finally, the Ramsay sedation scale (39) was not assessed in the present study; therefore the effect of Dex on the sedative state of an individual requires further investigation.

In summary, the present study investigated the effects of using $0.25 \mu \mathrm{g} / \mathrm{ml}$ Dex and $0.25 \mu \mathrm{g} / \mathrm{ml}$ sufentanil as adjuvants to $0.1 \%$ ropivacaine for labor analgesia. The combined adjuvant group displayed an improved analgesia effect, quicker onset time, reduced need for local anesthetics and decreased rate of pruritus compared with sufentanil $(0.5 \mu \mathrm{g} / \mathrm{ml})$. In addition, compared with Dex $(0.5 \mu \mathrm{g} / \mathrm{ml})$, the combined adjuvant group displayed reduced motor blockage. However, Dex is not licensed for epidural use and its safety requires further investigation. The results of the present study indicated that the combined use of Dex and sufentanil increased the effectiveness of the local anesthetic agent during epidural labor.

\section{Acknowledgements}

Not applicable.

\section{Funding}

No funding was received.

\section{Availability of data and materials}

The datasets used and/or analyzed during the present study are available from the corresponding author on reasonable request

\section{Authors' contributions}

YUL designed and supervised the study. GL, YX, XW, JS and YOL conducted the study and collected the data. XQ and HW performed the data analysis. GL wrote the paper. XW, JS and YOL help revised the manuscript. GL and YX contributed equally to the work. All authors read and approved the final manuscript.

\section{Ethical approval and consent to participate}

The present study was approved by the Shenzhen Maternity and Child Healthcare Hospital Ethics Committee (approval no. SZFY2018020798) and registered with the Chinese Clinical Trial Registry Center on Feb 23, 2018 (registration no. ChiCTR-IOR-1800014943). Written informed consent was obtained from all parturient women.

\section{Patient consent for publication}

Not applicable.

\section{Competing interests}

The authors declare that they have no competing interests.

\section{References}

1. Veenhof AA, Vlug MS, van der Pas MH, Sietses C, van der Peet DL, de Lange-de Klerk ES, Bonjer HJ, Bemelman WA and Cuesta MA: Surgical stress response and postoperative immune function after laparoscopy or open surgery with fast track or standard perioperative care: A randomized trial. Ann Surg 255: 216-221, 2012. 
2. Keskin HL, Keskin EA, Avsar AF, Tabuk M and Caglar GS Pethidine versus tramadol for pain relief during labor. Int $\mathrm{J}$ Gynaecol Obstet 82: 11-16, 2003.

3. Elbohoty AE, Abd-Elrazek H, Abd-El-Gawad M, Salama F, El-Shorbagy M and Abd-El-Maeboud KH: Intravenous infusion of paracetamol versus intravenous pethidine as an intrapartum analgesic in the first stage of labor. Int J Gynaecol Obstet 118: 7-10, 2012 .

4. Lebovits AH, Zenetos P, O'Neill DK, Cox D, Dubois MY, Jansen LA and Turndorf H: Satisfaction with epidural and intravenous patient-controlled analgesia. Pain Med 2: 280-286, 2001.

5. Okholm C, Goetze JP, Svendsen LB and Achiam MP: Inflammatory response in laparoscopic vs. open surgery for gastric cancer. Scand J Gastroenterol 49: 1027-1034, 2014.

6. Bajwa SJ, Arora V, Kaur J, Singh A and Parmar SS: Comparative evaluation of dexmedetomidine and fentanyl for epidural analgesia in lower limb orthopedic surgeries. Saudi J Anaesth 5: 365-370, 2011.

7. Selim MF, Elnabtity AM and Hasan AM: Comparative evaluation of epidural bupivacaine-dexmedetomidine and bupivacaine-fentanyl on Doppler velocimetry of uterine and umbilical arteries during labor. J Prenat Med 6: 47-54, 2012.

8. Debon R, Allaouchiche B, Duflo F, Boselli E and Chassard D: The analgesic effect of sufentanil combined with ropivacaine $0.2 \%$ for labor analgesia: A comparison of three sufentanil doses Anesth Analg 92: 180-183, 2001.

9. Salgado PF, Sabbag AT, Silva PC, Brienze SL, Dalto HP, Módolo NS, Braz JR and Nascimento P Jr: Synergistic effect between dexmedetomidine and $0.75 \%$ ropivacaine in epidural anesthesia. Rev Assoc Med Bras (1992) 54: 110-115, 2008 (In Portuguese)

10. Al-Mustafa MM, Abu-Halaweh SA, Aloweidi AS, Murshidi MM, Ammari BA, Awwad ZM, Al-Edwan GM and Ramsay MA: Effect of dexmedetomidine added to spinal bupivacaine for urological procedures. Saudi Med J 30: 365-370, 2009.

11. Zhao Y, Xin Y, Liu Y, Yi X and Liu Y: Effect of epidural dexmedetomidine combined with ropivacaine in labor analgesia: A randomized double-blinded controlled study. Clin J Pain 33 319-324, 2017.

12. Zhang T, Yu Y, Zhang W and Zhu J: Comparison of dexmedetomidine and sufentanil as adjuvants to local anesthetic for epidural labor analgesia: A randomized controlled trial. Drug Des Devel Ther 13: 1171-1175, 2019.

13. Qi X, Li Y, Rahe-Meyer N, Huang X, Gu Y, Wang X, Li Y and Wen Y: Intrathecal dexmedetomidine as adjuvant to ropivacaine in hysteroscopic surgery: A prospective, randomized control study. Int J Clin Pharmacol Ther 54: 185-192, 2016.

14. Qi X, Chen D, Li G, Huang X, Li Y, Wang X and Li Y: Comparison of intrathecal dexmedetomidine with morphine as adjuvants in cesarean sections. Biol Pharm Bull 39: 1455-1460, 2016.

15. Chen C, Hei Z, Xing J, Zhu Q, Qiu R, Liu J, Gong C, Cheng N, Zhou S and Shen N: Laryngoscopic techniques modulate anaesthesiologists' perception of halitosis in patients: A randomised controlled trial. Eur J Anaesthesiol 36: 918-923, 2019.

16. Li X, Chen CJ, Tan F, Pan JR, Xing JB, Zhu QQ, Hei ZQ and Zhou SL: Effect of dexmedetomidine for attenuation of propofol injection pain in electroconvulsive therapy: A randomized controlled study. J Anesth 32: 70-76, 2018.

17. Congedo E, Sgreccia M and De Cosmo G: New drugs for epidural analgesia. Curr Drug Targets 10: 696-706, 2009.

18. Park SJ, Shin S, Kim SH, Kim HW, Kim SH, Do HY and Choi YS: Comparison of dexmedetomidine and fentanyl as an adjuvant to ropivacaine for postoperative epidural analgesia in pediatric orthopedic surgery. Yonsei Med J 58: 650-657, 2017.

19. Chen C, Huang P, Lai L, Luo C, Ge M, Hei Z, Zhu Q and Zhou S: Dexmedetomidine improves gastrointestinal motility after laparoscopic resection of colorectal cancer: A randomized clinical trial. Medicine (Baltimore) 95: e4295, 2016.

20. Wang F, Zhong H, Xie X, Sha W, Li C, Li Z, Huang Z and Chen C: Effect of intratracheal dexmedetomidine administration on recovery from general anaesthesia after gynaecological laparoscopic surgery: A randomised double-blinded study. BMJ Open 8: e020614, 2018.

21. Zeng X, Jiang J, Yang L and Ding W: Epidural dexmedetomidine reduces the requirement of propofol during total intravenous anaesthesia and improves analgesia after surgery in patients undergoing open thoracic surgery. Sci Rep 7: 3992, 2017.
22. Helal SM, Eskandr AM, Gaballah KM and Gaarour IS: Effects of perineural administration of dexmedetomidine in combination with bupivacaine in a femoral-sciatic nerve block. Saudi J Anaesth 10: 18-24, 2016.

23. Abdallah FW, Dwyer T, Chan VW, Niazi AU, Ogilvie-Harris DJ, Oldfield S, Patel R, Oh J and Brull R: IV and perineural dexmedetomidine similarly prolong the duration of analgesia after interscalene brachial plexus block: A randomized, three-arm, triple-masked, placebo-controlled trial. Anesthesiology 124: 683-695, 2016.

24. Sztain JF, Gabriel RA and Said ET: Thoracic epidurals are associated with decreased opioid consumption compared to surgical infiltration of liposomal bupivacaine following video-assisted thoracoscopic surgery for lobectomy: A retrospective cohort analysis. J Cardiothorac Vasc Anesth 33: 694-698, 2019.

25. Peterson NW, Buote NJ and Bergman P: Effect of epidural analgesia with opioids on the prevalence of urinary retention in dogs undergoing surgery for cranial cruciate ligament rupture. J Am Vet Med Assoc 244: 940-943, 2014.

26. Qin M, Chen K, Liu T and Shen X: Dexmedetomidine in combination with sufentanil for postoperative analgesia after partial laryngectomy. BMC Anesthesiol 17: 66, 2017.

27. Shukla U, Prabhakar T, Malhotra K and Srivastava D Dexmedetomidine versus midazolam as adjuvants to intrathecal bupivacaine: A clinical comparison. J Anaesthesiol Clin Pharmacol 32: 214-219, 2016

28. Wangping $\mathrm{Z}$ and Ming R: Optimal dose of epidural dexmedetomidine added to ropivacaine for epidural labor analgesia: A pilot study. Evid Based Complement Alternat Med 2017: 7924148, 2017.

29. Koraki E, Stachtari C, Kapsokalyvas I, Stergiouda Z, Katsanevaki A and Trikoupi A: Dexmedetomidine as an adjuvant to $0.5 \%$ ropivacaine in ultrasound-guided axillary brachial plexus block. J Clin Pharm Ther 43: 348-352, 2018.

30. Bazin M, Bonnin M, Storme B, Bolandard F, Vernis L, Lavergne B, Pereira B, Bazin JE and Dualé C: Addition of clonidine to a continuous patient-controlled epidural infusion of low-concentration levobupivacaine plus sufentanil in primiparous women during labour. Anaesthesia 66: 769-779, 2011.

31. Eisenach JC, Shafer SL, Bucklin BA, Jackson C and Kallio A: Pharmacokinetics and pharmacodynamics of intraspinal dexmedetomidine in sheep. Anesthesiology 80: 1349-1359, 1994.

32. Marhofer P and Brummett CM: Safety and efficiency of dexmedetomidine as adjuvant to local anesthetics. Curr Opin Anaesthesiol 29: 632-637, 2016

33. Yang YC, Meng QT, Pan X, Xia ZY and Chen XD: Dexmedetomidine produced analgesic effect via inhibition of HCN currents. Eur J Pharmacol 740: 560-564, 2014

34. Sun L, Zhou J and Sun C: MicroRNA-211-5p enhances analgesic effect of dexmedetomidine on inflammatory visceral pain in rats by suppressing ERK signaling. J Mol Neurosci 68: 19-28, 2019.

35. Zhang X, Wang D, Shi M and Luo Y: Efficacy and safety of dexmedetomidine as an adjuvant in epidural analgesia and anesthesia: A systematic review and meta-analysis of randomized controlled trials. Clin Drug Investig 37: 343-354, 2017.

36. Boselli E, Debon R, Duflo F, Bryssine B, Allaouchiche B and Chassard D: Ropivacaine $0.15 \%$ plus sufentanil $0.5 \mathrm{microg} / \mathrm{ml}$ and ropivacaine $0.10 \%$ plus sufentanil $0.5 \mathrm{microg} / \mathrm{ml}$ are equivalent for patient-controlled epidural analgesia during labor. Anesth Analg 96: 1173-1177, table of contents, 2003.

37. Illuzzi JL, Greenberg JT and Mancini PA: Epidural analgesia during the second stage of labor: A randomized controlled trial. Obstet Gynecol 131: 742, 2018.

38. Shen X, Li Y, Xu S, Wang N, Fan S, Qin X, Zhou C and Hess PE Epidural analgesia during the second stage of labor: A randomized controlled trial. Obstet Gynecol 130: 1097-1103, 2017.

39. Yan MJ, Wang T, Wu XM and Zhang W: Comparison of dexmedetomidine or sufentanil combined with ropivacaine for epidural analgesia after thoracotomy: A randomized controlled study. J Pain Res 12: 2673-2678, 2019.

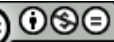

This work is licensed under a Creative Commons Attribution-NonCommercial-NoDerivatives 4.0 International (CC BY-NC-ND 4.0) License. 